\title{
A Twin Approach to Internet Service Provision in Sparse Rural Community in Nigeria
}

\author{
Kuboye B.M. , Alese B.K, Imasuen F. I. \\ Department of Computer Science, the Federal University of Technology, Akure, Ondo State, Nigeria
}

\begin{abstract}
Today Internet is the tool that provides the fastest and latest information on what goes on around including Nigeria. In Nigeria, most of the rural areas are still lagging behind in the area of Internet provision. This work focuses on the provision of Internet services to a sparse rural co mmunity based on the apprehension of the people of the rural settlement in Nigeria, taking Ake-Ih ievbu sparse rural community as a case study. It explores the various methodologies that are used in providing internet services and fashion out model that will be best suited for sparse rural communities with emphasis on affordability to the people and profit marg in returns to the providers. This model is in two parts; Fixed and cellular wireless. Fixed wireless involves the use of Very Small Aperture Technology (VSAT), Fixed Wireless and Wireless Local Area Network (WLAN) technologies, to allow the Internet Service Providers to redistribute the internet service around the settlement and allowing the ind igenes to access it via their personal co mputers using wireless radio signal. The use of Fixed Wireless and Local Area Network (LAN) technologies to redistribute it to cyber cafes, for those whose cannot afford to own a personal computer is also presented. Cellular technologies involve the use of cellular mobile technologies like Global system for Mobile Communications (GSM) to provide Internet services to the commun ity. Considering the cost of building base stations for cellu lar mobiles, the possibility of government and corporate organizations partnering with GSM operators to reduce the cost, thereby providing affordable Internet access for the rural dwellers is also presented. The provision of Internet to the rural co mmunities in Nigeria will be greatly overco me, if the models presented here are strictly adhered to.
\end{abstract}

Keywords Cellular, GSM, Internet, VSAT, W ireless, WLAN

\section{Background of the Study}

The world is fast becoming a global village and a necessary tool for this process is access to information on what is happening around us and the world at large, of which Internet is a key element. There are about 76 million active mobile subscribers in Nigeria[1]. This is only about half of the nation's population of 165 million. The digital divide is still wide even though dwellers in rural communities desire to be connected to the rest of the world.

In Nigeria, the rural areas constitute the greater percentage of the country's population. This sector of the country is economically backward and the gap between rural and urban sectors in the country has been widening in the recent years with poverty being very widespread among Nigerian rural communities[2]. This led to the yearnings of rural communities' dwellers to be connected to the rest of the world through the Internet provision technologies.

Wikipedia defined Internet as a global system of

* Corresponding author:

kubonline@yahoo.co.uk (Kuboye B.M.)

Published online at http://journal.sapub.org/ijnc

Copyright (C) 2012 Scientific \& Academic Publishing. All Rights Reserved interconnected computer networks that use the standard Internet protocol suite (TCP/IP) to serve billions of users world wide[3]. A lso, another online definition of Internet is given as an international computer network providing e-mail and information from computers in educational institutions, government agencies, and industry, accessible to the general public via modem links [4]. Internet service provision is the act of providing Internet connectivity to a group of people, an environment, place and homes. This is usually done by Internet service providers. According to Doczi[5], Internet was one of the tools in bridging the gap between the ICT disadvantaged and advantaged people.

Internet is the engine of the information superhighway of our information era in which we live. Therefore, it allows you to download and upload a lot of information, music, videos, and attachments. Also, Internet allows millions of people to contact each other across the continents. It is the most global market known to man; virtually everything can be bought on the Internet. It is also a source of employment search where employee and employer can meet. Internet has been a platform for education where a lot of people can get quality degrees from reputable institutions without leaving their towns or villages. Health resources for healthy living are abundance on the internet. The list is endless of what internet can do for users. 
Moreover, as Nigeria is now moving towards e-voting system, it will be impossible for e-voting to take place in the rural communities since e-voting involves transmission of ballots and votes through private computers networks, or the internet. Therefore there is urgent need to connect the rural areas in Nigeria if the e-voting will be a success. However, some of the people in the rural areas have never touched computer sets before and have no idea about the Internet. As a result, Internet Service Providers do not consider such areas an economically viable and therefore, no attention was given to them.

There have been a lot of efforts in bridging the gap between rural dwellers and city dwellers in Africa and especially in Nigeria. The Federal Government of Nigeria realized that the country was lagging behind in the race to become a digital society, and saw the potential of information and communication technology (ICT) to empower people - particularly, people with disabilities, wo men, youth and rural commun ities. There fore, it declared Information and Communication Technologies (ICTs) a national priority, in the year 2001[6]. Federal government created the Universal Service Provision Fund (USPF) in 2003 under the Nigerian Communications Act[7]. The USPF was mandated to promote widespread availability and usage of network services throughout Nigeria by encouraging the installation of network facilities and the provision of network services to underserved areas.

On the 25th August, 2011, Federal government set up an ad-hoc committee to harmonize all the various ICT policy in Nigeria. The report submitted by this ad-hoc committee in January, 2012 stated that out of 160 million Nigerians only 40 million are Internet users [8]. It is very disheartening that nothing was reported about the rural Internet penetration which is very vital if Nigeria is going to be truly transformed and meet the vision 20:20:20. All these efforts are to bridge the gap between the rural and urban dwellers so as to minimize the rural-urban drifts in Nigeria. Despite all these moves, most of the rural communities still lack access to the Internet services.

How can we provide a good, affordable and fast Internet service for prompt access to information for the dwellers of the rural communities in Nigeria? Affordability is a watch word here, since most people in these communities are low income earners and such, the provision of Internet facilities, should boost their economic powers and not to create more power level. The need to satisfy the indigenes quest for access to current and easily affordable information should be to the advantage of both the providers and the users. The success of Internet provision project in rural community depends on sustainability and deployment of suitable infrastructures [9]. The objective of carry ing out this research is to determine the best technology to provide Internet services to the rural community, which will be affordable for the indigenes of the community, the Government and brings profit to the providers.

A framework of possible technologies available for provision of Internet is considered here ranges from the wired to wireless technologies. Analys is of each technology available for Internet service provision to the rural communities is also considered. The research provides a-two-legged solution using the fixed wireless and cellular wireless. Also, possible provision of a co mmunity cybercafé is also considered for those that cannot afford to have a PCor that cannot afford the Internet subscriptions. In each of the solution, combination of best technologies for Internet service provision that would be affordable for the indigenes of the rural communities and the government are considered.

\section{Technologies Reviews}

\subsection{Wi-Fi technology}

The wireless fidelity (Wi-Fi) or wireless local area networking (WLAN) uses 802.11 standards that share two unlicensed frequency bands at $2.4 \mathrm{GHz}$ and $5 \mathrm{GHz}[10]$. Two versions of 802.11 were specified, a frequency hopping spread spectrum (FHSS) version and a direct sequence spread spectrum(DSSS) version, both in the $2.4 \mathrm{GHz}$ part of the spectrum. The standard has been enhanced and replaced now with IEEE $802.11 \mathrm{~b}$. IEEE $802.11 \mathrm{~b}$ enhanced the DSSS mode of 802.11 with a data rate up to $11 \mathrm{Mbps}$. Wi-Fi is a wireless technology that uses radio signals of high frequency to transmit data from one device to another. It only operates on several hundred feet[11]. Wi-Fi technology is used in small-scale areas, such as a house or office, where a router (a transmitter) is set up to provide Internet connectivity to computers in the group, without the use of wires. In the Wi-Fi system, computers are connected with wireless network card and this is further connected to WLAN terminals to access the network via the access point (AP) which is linked to the access router. The router is connected to the modem through a cable. Any other user who wants to access the internet through this network can connect to this network wirelessly within the range of 300 to 600 feet from the access point after getting a permission of the administrator[7].

\subsection{Microwave Technology}

Microwaves are electro magnetic waves with wavelengths ranging from as long as one meter to as short as one millimetre, or equivalently, with frequencies between 300 $\mathrm{MHz}(0.3 \mathrm{GHz})$ and $300 \mathrm{GHz}$. For applications where high capacity Internet is needed, such as, metropolitan networks or links between remote buildings, mic rowave links is provided in the range from $10 \mathrm{Mbps}$ to $200 \mathrm{Mbps}$ between two or more locations. A microwave link is a high speed, cost effective alternative to leased lines or fiber optic cables. A microwave link is ideally suited for Inter-building LAN, voice and video connections, broadband Internet connectivity and so on.

\subsection{VSAT Technology}

Very Small Aperture Terminal (VSAT) technology is a 
telecommunication system based on wireless satellite technology. VSAT technology is made up of a small satellite earth station and a typical antenna of 1.8 meter diameter. VSAT configuration is made up of two segments: earth segment and space segment. The earth segment has equipment both at the central hub and at the remote locations while the space segment links VSAT to and from the satellite. Satellite segments in the sky serves as a radio frequency repeater when VSAT send information to the satellites in the sky, it is received, amplify the information and then retransmit on a higher frequency[13].

\subsection{Mobile Broadband}

This represents wireless data communication technologies that utilize mobile phone radio spectrum for cellular networks to deliver Internet access almost anywhere. The service can be accessed through a mobile phone and USB data-only modems or PCMCIA (Personal Computer Memory Card International Association) data card. Mobile services are typically delivered over a wide range of radio frequency spectrum bands (e.g. $900 \mathrm{MHz}, 1800 \mathrm{MHz}$, $2.6 \mathrm{GHz})$, most of which can also be reached indoors.

\section{Feasibility Study}

The feasibility study provides information in order to justify the ess ence of this work. It involves visiting the sparse rural community used as case study and confirms the possibility of establishing a network in the area. This was done by making a wide tour survey to the community and mapping out strategic locations for the implementation of Very Small Aperture Terminal (VSAT) technology using fixed wireless technology to re-distribute the Internet service to each sparse settlement. Also, the possibility of establishment of a cyber café to cater for those that do not have the privilege of owning a personal computer was carried out. In doing this, the criteria enumerated here for the implementation of the project, form the basis of the requirements:

- Specification of the brand of computer systems to be used, peripheral requirements in term of Uninterrupted Power Supply (UPS), voltage stabilizer and so on.

- Consideration of the proximity of the sparse settlements to each other so as to know the appropriate communication facilities needed.

- Specification of the appropriate needed facilities and the type of technology needed for the Internet redistribution.

- Designing of the map of the rural communities which will be used as a guide to implement the technology in the area

The diagram in fig 1.0 demonstrates how Internet service is obtained from the ISP and distributed round the rural area.

From the diagram designed, three implementation categories are needed to be analysed for the effective implementation of an Internet network in the sparse location:
- The base station and redistribution to its immediate environment (which in this case is the palace area)

- Connection of the rural settlements together

- The computer centre/ cyber-café

Each of the categories is analysed properly in order to know the kind of technology to be implemented and how it is done

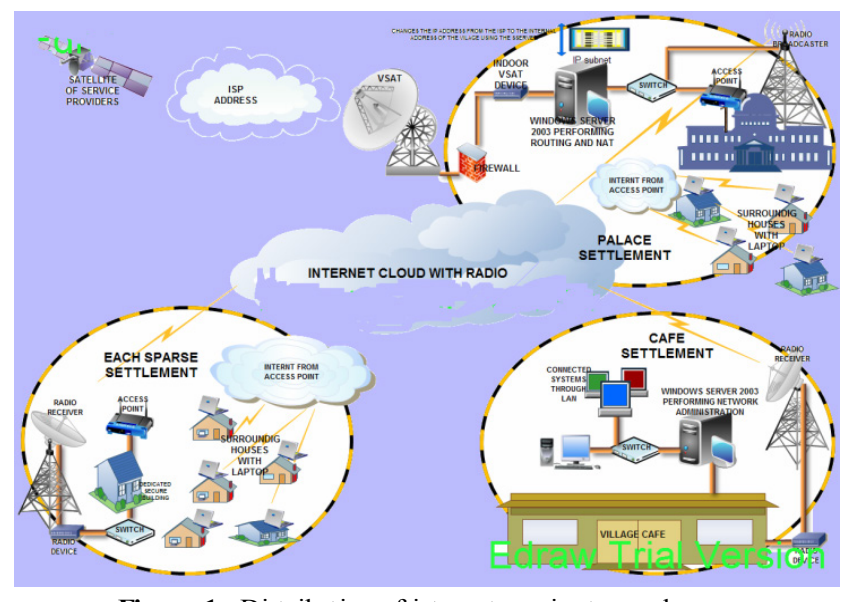

Figure 1. Distribution of internet service to rural areas

\subsection{The Base Station}

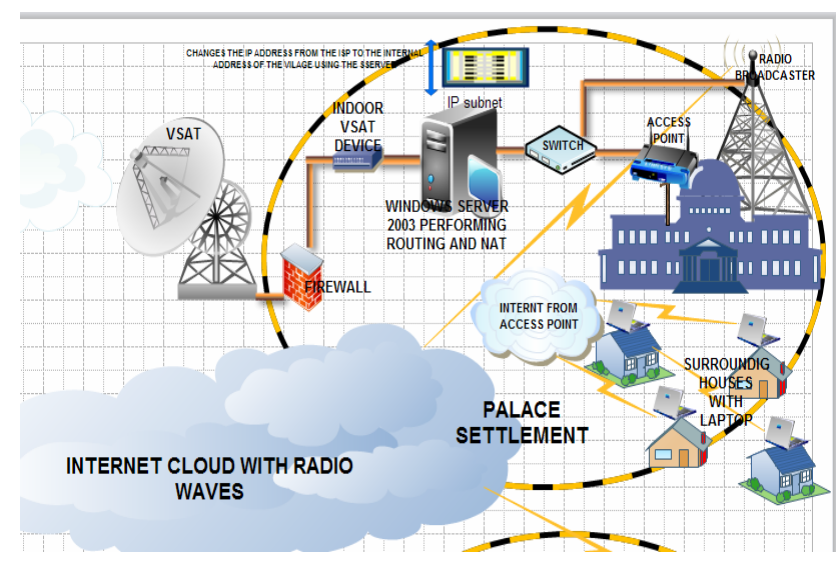

Figure 2. Server workstation area

The survey highlighted the king's palace area of the rural community as the best suitable area for the base station based on the standards for the implementation of the VSAT technology that serves as the source of internet from the ISP. It is also of high importance to highlight the other kinds of fixed wireless technology also needed to be implemented:

- A server system (router and a network address translator NAT)

- A radio broadcaster (boosting of signals to other sparse settlement)

- Wireless router (access point)

- Switching network

The pictorial drawing of the facilities is shown in the fig 2 .

\subsection{Work flow of the Internet from the ISP to the Village Channel}

For the purpose of clarity and ease of implementation, it is 
advised to draw a work flow of the internet channel from the ISP to the village. Fig 3.0 shows the detailed channel flow of internet connection from the ISP to the village with the detailed exp lanation given below;

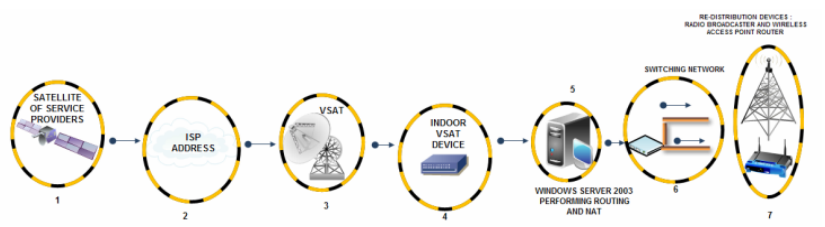

Figure 3. Work flow of the internet from the ISP to the village channel

The ISP provides the Internet connection via the VSAT connected to the satellite to the village. VSAT serves as the receiver of the Internet signal coming from the ISP. The satellite transmits the signal from the ISP to the VSAT; thereafter, the signal is accepted and decoded by the modem connected to the VSAT. The internet connectivity then goes in to the server through the fire wall which serves as a means of security for the network of the rural area. The server translates the IP address given by the ISP into an address that will be sub-netted and then shared by all the users in the village. The server also allows all the users in the village to connect dynamically to the internal network connected to the internet which has been enabled in the DHCP section of the server. Due to the need to broadcast signals to other sparse settlement far away from the base station, the signals are broadcasted by the radio broadcaster that is connected to switch. Then, the radio receiver will get the radio signals and pass it onto the indoor radio device and to the AP via the switch. Afterwards, the Internet will be connected via AP's by the Villagers on their systems or Cybercafés.

Making sure that there is an established connection in the base station is very important to the redistribution of the internet facility to other parts of village. This is done by actually testing the connection created above which has been documented above. To set up Internet connectivity in all the sparse settlement, some devices are therefore needed to be put in place so as to ensure effective connection, these are, the radio receiver, the and access points as shown in fig 4.0. They are all configured in the same way the base station equipments are configured with a slight difference, that is, radio receiver was used instead of a radio broadcaster. The path way of workflow from each sparse settlement is shown in fig 4.0.

\subsection{Work fl ow of Internet to Each S parse Settle ment}

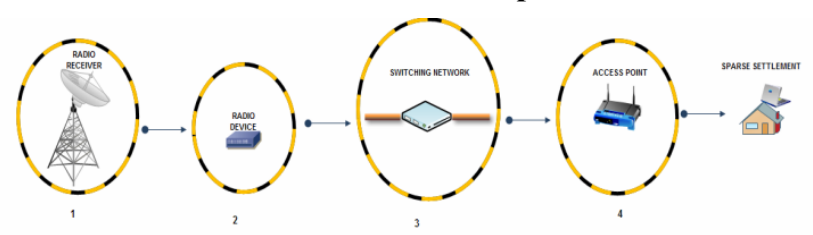

Figure 4. Work flow of int ernet to each sparse settlement

At this juncture, the base station and those living around it have been fully connected to the network, then, there is need to broadcast the signal to all other network in the sparse settlements. The radio signal is broadcasted by the radio broadcaster in the base station; the signal is received, then radio indoor device then decodes and transmits the signal received into network connection by the device. The radio device is then connected to the switch which is used to distribute the network connection into multiple connections just as it has been done in the base station but via access point (AP). AP has been installed and configured in each sparse location for network connectivity so that all users can connect wire lessly to the network. The access points extend the Internet connectivity from the base station to users in the sparse settlement.

\subsection{Cybercafé Set-up}

The aim of this work to make sure everybody in the village is connected to the Internet or should be able to have access to the Internet. Putting this into consideration, there might be those living in the village that does not have the sufficient privilege to own a personal computer that could connect wirelessly to the internet service provided to the locality. There is a need to set up a network of locally connected computers that can access the computers using local area network (LAN) connection as the main mode of connection to the Internet.

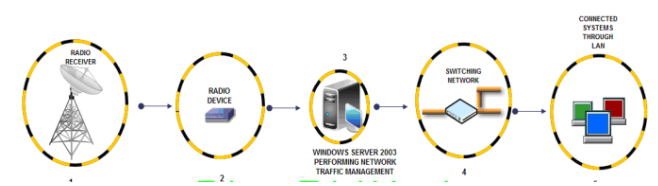

Figure 5. Work flow of the café

The workflow starts from the radio receiver which receives the signal fro $m$ the base station as shown in fig 5.0. The received signal is decoded and transmitted into network connection by the indoor radio device connected to the radio receiver. The radio receiver is connected to a server that serves as a network admin istration server to ma intain traffic from all the systems connected to the internet in the café. The server is now connected to the switch which forms the local area network of the café. The switch duplicates connection to as many systems connected in the café.

\section{Mobile Cellular Approach in the Sparse Rural Settlement}

The major advances to the GSM technology that has made the deployment of higher technology like GPRS, EDGE possible are analysed. The deployment of GSM and its upgrade through GPRS to EDGE and UMTS, which is the major $3 \mathrm{G}$ technology that is compatible with the GSM, is presented here. Considering the level of cellular mobile telephone penetration as stated by the Ad-hoc committee on ICT policy integration that telephone users has moved from 400,000 fixed line to about 90.1 million mobile phone users as at first quarter of 2011 [8]. Internet connection to the rural areas can be enhanced considering the co-location and 
government or corporate partnerships[7]. The possibility of mobile cellu lar broadband in the rural settlement is very high, since there was already an existing mobile network (example, MTN) in the village, as it in other rural communities around the country. So, just like the way people load recharge card on their mobile phones to make voice calls across to people in and outside the community, MTN recharge cards are loaded on a modem that access the packet switched Data services. One of the obvious limitations of Mobile coverage of rural areas is the fear of recovering the expended money in building and maintaining base stations. Electricity and security are also major factors to be considered in maintaining base stations in Nigeria. Therefore, the model discussed here can serve as a major step in solving the aforementioned problems.

\subsection{Some Mobile Cellular Networks Currently Providing Internet Services in Nigeria}

\subsubsection{MTN}

MTN is one of the largest Internet Service Providers (ISP) in Africa and the largest in Nigeria. It offers an array of broadband plans that allow access to high speed broadband Internet access through their integrated network of HSDPA-3G, EDGE and GPRS technologies. The MTN 3G compatible or Data modem automatically chooses the fastest connection available depending on the location, making the process simple and effective and leaving the customer free to search the web without needing to understand all the various technologies[13]. MTN's 3.5G Mobile Broadband is the fastest and most reliable way to access the Internet. It helps you stay connected at almost any time, and makes your business, personal information and entertainment as mobile as you are, when you are working within MTN's coverage areas[14]. With 3.5G Broadband MTN customers will benefit from down load data speed up to 4-5 times faster than currently available. MTN's 3.5G Mobile Broadband access provides convenient, mobile High Speed Internet access for browsing, blogging, checking e-mails, chatting and social Networking, music downloads and so on. MTN's 3.5G broadband access is available to all customers, as soon as you subscribes to the MTN network and buy the MTN modem for Internet access.

\subsubsection{Globalcom(Glo Mobile)}

GLOBALCOM (Glo mobile) had launched 4G mobile technology based on technology LTE in Nigeria. What made this special is that some networks in some advanced countries are just deploying or are yet to deploy 4G-LTE. For example, Verizon wireless in the United States just launched its 4G network also based on LTE in December, 2010, while AT\&T also in the United States launched their 4G net work in the second quarter of 2011[13]. This made Glo mobile the first network to go beyond $3.5 \mathrm{G}$ mobile technology in Nigeria. LTE promises super-fast data transfer with downlink peak rates of at least $100 \mathrm{Mbps}$, and uplink of at least 50 Mbps (www.nigerianelites forum.com). With Glo 4G videos downloads, software downloads (like software updates for mobile phones), and video streaming will be faster. Glo 4G will also make services like interactive TV, mobile TV, multi-player online gaming, and video on demand possible or better in Nigeria. According to the Glo CEO, Mr. Mohamed Jameel, the 4G services have been deployed in over 100 sites in Lagos alone[16].

\subsubsection{Et isalat}

Et isalat offers fixed line services over its Next Generation Network, and provides mobile users with a range of services and applications such as GPRS, 3G, Blackberry and Mobile Cam. Etisalat provides broadband Internet access to the entire UAE and is currently working on rolling out triple play services, which will incorporate high-speed Internet, TV and fixed line offerings all via one cable known as Triple Play Services. In addition to voice and data networks, Et is alat a lso has many other offerings including the E-Vision cable TV network[17]. Etisalat is also the majority shareholder in Thuraya, a leading provider of satellite co mmunications [17]. Et isalat, though a new entrant in GSM networks in Nigeria, has strived to meet the challenges posed by other GSM networks.

\subsubsection{Starco ms}

Starcoms is operating with Code Division Multiple Access (CDMA). It started with the deployment of CDMA single carrier radio transmission technology called CDMA1xRT T which has data rates up to $144 \mathrm{Kbps}$. It has moved up by investing a lot in new technology to boost its network expansion. The package includes deployment of the Enhanced Voice Data Only services (EVDO) release A. EVDO, is CDMA's answer to the need for high speed broadband services, its speeds is as high as 300-400 kilobits per second (kbps). Starcoms is providing EVDO services currently in Lagos, Abuja and Port Harcourt[18].

\subsubsection{Vis afone}

It is the largest Code Division Multiple Access (CDMA) network operator in Nigeria. The acquisition of Multi-Links Telkom's by the Visafone make it to be the Nigeria's largest CDMA operator and is on a mission to prove that CDMA technology can compete effectively alongside GSM technology. The acquisition of Multi-Links Telkom's CDMA network heralds another phase in Nigeria's nascent telecommunications market[13]. Also, they offer the lowest priced services in voice and data services in Nigeria as at present. They also deploy CDMA EDVO presently in Nigeria in addition to the CDMA single carrier radio transmission technology, CDMA1xRTT which has data rates up to $144 \mathrm{Kbps}$.

\subsection{Government and Cor porate Organizations Partnership with GS M Operators}


One of the reasons hindering GSM operators from providing internet services to the rural community is the fact that the profit returns is usually very low compared to the cost incurred in establishing the base stations and the installation of the mast[19]. The cost of building a base station and its maintenance is very high. The operators have to buy the land, antennae, transmitters, generator and employ security personnel before a base station site can stand. Thus, no service provider operator would want to invest a lot of money into a project that yields little or no returns. The low profit returns is usually due to the low inco me earnings of the people of the rural communities and the low population compared to the urban communities. To solve this problem, government can partner with the network operators in many ways. Government can invest in building the sites and lease them to the operators. Government can strengthen Power Holding Company of Nigeria (PHCN) so that there can be constant supply of electricity. Also, they can build base stations and install the mast and antennae.

When all these have been put in place, then, government can now lease them to the operators. This option will lead to the model of site sharing or co-location among the operators[20]. The operators will install their own branded facilities on the site. Since different operators have different branded facilities, and as a result, there cannot be any radio interference between the operator's services. This is a method practiced in most civilized country. The operators can employ the services of one of the security outfits to guard their infrastructures. If this model is adopted, it will remove the burden of building site thereby reduce the operational expenses and the price of the data charged per gigabyte. It will allow the operators to quickly deploy GSM services in the rural communities that will enable both voice communication and Internet access.

\section{Conclusions}

This paper shows how Internet can be provided to rural communities with the state of the art technologies that will be to the gain of the providers and rural subscribers. Emphas is was made on using the best combination of fixed wireless technologies and cellular wireless technologies to provide Internet connection. It also shows how Government can assist the providers in providing some essential services such as constant electricity, building stations and erecting mast. It also reveals how co-location of cellular providers' channels in one base station can help reduce the cost of building and maintaining base station.

\section{REFERENCES}

[1] Jegede O. "An integrated ICT-support for ODL in Nigeria". The vision, the mission and the journey so far, 2002. Available at: http://www.ukhap.nic.in/ict/docs/s3/jegede.doc

[2] Torimiro C. M. and McLay, "Community Internet Access in Rural Areas: Solving the Economic Sustainability Puzzle", the Global Information Technology Report 2001-2002: Oxford University

[3] www.wikipaedia.com

[4] www.google.com

[5] Doczi Y., "The Good Research Guide for Small-Scale Social Research Projects", Open University Press. Buckingham, 2000 .

[6] Bello H. M., "The Role of Information and Communication Technology in the Fight against Poverty - The Nigerian Experience". (Paper presented at the Symposium on ICT and the Society of Information. 9th-11th December 2002. Algiers). Available at: http://allafrica.com/stories/20030120 0386.html.

[7] Imasuen, F., "A Model For Internet Service Provision to a Sparse Rural Community", A first degree thesis submitted to Federal University of Technology, Akure, November, 2011

[8] National Information Communication Technology (ICT), policy draft by the ministerial committee on ICT policy harmonization. January 2012

[9] Disraeli b., "Information Technology for the Development of Youth in Africa", 2001. Available online at: http://www.ay f.de/documents/dixit.doc

[10] Guo y. And jay, "Advances in Mobile Radio Access Networks" Artech house, Inc, ISBN 1-58053-727-8. 2004.

[11] Saarbrucken and Hermann (2003), "Providing Low-Cost Information Technology Access to Rural Communities in Developing Countries: What Works? What Pays?" Web Doc Series - OECD Development Centre, Paris, France June 2003, available online: http://www.developmentgateway.org last accessed 26 April 2004

[12] Al Hammond \& John Paul, "A New Model for Rural Connectivity" World Resources Institute, May 2006

[13] www.ittelecomdigest.com.

[14] www.mtnnigeria.com

[15] www.nigerian elitesforum.com

[16] www.naijatechguide.blogspot.com.

[17] www.etisalat.com

[18] www.starcomms.com/files/3g pioneer.pdf.

[19] Kuboye B.M.., Optimization Models for Minimizing Congestion in Global System for Mobile Communications (GSM) in Nigeria" Journal of Media and Communication Studies vol. 2(5), pp.122-126, ISSN 2141- 2545, May 2010. [ available on line at: www.academicjournals.org/jmcs

[20] www.planningportal.gov.uk 